\title{
Combinatorial Expression of Three Zebrafish Genes Related to Distal-Less: Part of a Homeobox Gene Code for the Head
}

\author{
Marie-Andrée Akimenko, ${ }^{1,2,3}$ Marc Ekker,, ${ }^{1,2,3}$ Jeremy Wegner, ${ }^{4}$ Wei Lin, ${ }^{1}$ and Monte Westerfield ${ }^{4}$ \\ ${ }^{1}$ Loeb institute for Medical Research, Ottawa, Ontario, Canada, K1Y 4E9, Departments of ${ }^{2}$ Medicine and ${ }^{3}$ Anatomy, \\ University of Ottawa, Ottawa, Ontario, Canada, and ${ }^{4}$ Institute of Neuroscience, University of Oregon, Eugene, Oregon \\ 97403
}

\begin{abstract}
We describe analysis of zebrafish distal-less-related homeobox genes that may serve as specifiers of positional information in anterior regions of the CNS and in peripheral structures. We isolated three zebrafish genes, $d / \times 2, d / \times 3$, and $d / x 4$, by screening embryonic cDNA libraries. Comparisons of the predicted sequences of the Dlx2, Dlx3, and Dlx4 proteins with distal-less proteins from other species suggest that vertebrate distal-less genes can be divided into four orthologous groups. We observed similarities but also unique features of the expression patterns of the zebrafish dlx genes. Among the three genes, $d / \times 3$ alone is expressed during gastrulation. Shortly after gastrulation, cells in the ventral forebrain rudiment express $d / \times 2$ and $d / \times 4$, but not $d / \times 3$, and hindbrain neural crest cells express only dlx2. Presumptive precursor cells of the olfactory placodes express $d / x 3$ and $d / \times 4$ but not $d / \times 2$. Transcripts of $d / \times 3$ and $d / \times 4$ are present in overlapping subsets of cells in the auditory vesicle and in cells of the median fin fold, whereas $d / x 2$ is never expressed in the auditory vesicle and only at low levels in localized regions of the median fin fold. Cells of the visceral arches and their primordia express all three $d / x$ genes, but with different developmental time courses. We suggest that combinatorial expression of the $d / x$ genes is part of a homeobox gene code specifying pattern formation or cell fate determination in the forebrain, in peripheral structures of the head, and in the fins.
\end{abstract}

IKey words: branchial arches, cranial neural crest, ear, fin, forebrain, homeobox gene]

In vertebrates, homeodomain proteins may participate in the coding of positional information during the development of segmented structures (McGinnis and Krumlauf, 1992). The homeodomain, a highly conserved DNA-binding domain, has been found in the product of a large number of genes that encode putative or known transcription factors. The most widely studied vertebrate homeobox genes are members of the four mammalian Hox gene complexes that belong to the Antennapedia class, as deduced from sequence comparisons (Boncinelli et al.,

\footnotetext{
Received Sept. 10, 1993; revised Nov. 22, 1993; accepted Nov. 30, 1993.

We thank Tom Schilling and Steve Wilson for helpful discussions and advice, Daniel Bégin for technical assistance, D. J. Grunwald for cDNA libraries, Vijay Kapal for his help with tissue sections, and Corinne Houart and Charles Kimmel for critical reading of the manuscript. This research is supported by grants from the MRC of Canada to M.-A.A. from the NCI of Canada to M.E., and from the NIH HD 22486 and the McKnight Foundation to M.W. M.E. is an MRC Scholar.

Correspondence should be addressed to Monte Westerfield at the above address.

Copyright (C) 1994 Society for Neuroscience $0270-6474 / 94 / 143475-12 \$ 05.00 / 0$
}

1988; Gaunt et al., 1988; Duboule and Dollé, 1989; Graham et al., 1989).

Combinations of functionally active Hox genes, or Hox codes, are thought to play a determinant role in the development of the vertebrae (Kessel and Gruss, 1991), the hindbrain, the branchial arches (IIunt et al., 1991a,b), and the limbs (Morgan et al., 1992). Combinatorial expression of Hox genes may specify the identity of vertebral segments, as suggested by the homeotic transformations produced by alterations in the expression patterns of the Hox genes by either ectopic expression (Kessel et al., 1990; Kessel and Gruss, 1991; Jegalian and DeRobertis, 1992) or loss of function (Wright et al., 1989; Le Mouellic et al., 1992). The mouse HoxA7 gene placed under the control of the chicken $\beta$-actin promoter was ectopically expressed in regions anterior to its normal boundary of expression, resulting in the formation of an additional vertebra, the proatlas (Kessel et al., 1990). A targeted null mutation in the Hox $C 8$ gene resulted in anterior transformation of several skeletal segments (Le Mouellic et al., 1992). In the avian limb bud, alteration of HoxD11 expression and, consequently, of the combinatorial expression of the HoxD complex genes produced a posterior homeotic transformation (Morgan et al., 1992). In these cascs, although not in others (Pollock et al., 1992), the homeotic transformations obeyed a rule analogous to the posterior transformation rule furst suggested in Drosophila (Lewis, 1978; McGinnis and Krumlauf, 1992). The molecular mechanisms by which combinations of active $H o x$ genes determine segment or digit identities are presently unknown, and genetic coding of positional information in other regions of vertebrate embryos, particularly the head, has yet to be elucidated.

Here we describe the cloning of three zebrafish homeobox genes, $d l \times 2, d l \times 3$, and $d l \times 4$, that belong to the distal-less family of genes and that may specify positional information in the head. Vertebrate members of the distal-less family include the mouse $D l x 1$ and $D l x 2$ (Tes-1) genes (Porteus et al., 1991; Price et al., 1991; Robinson et al., 1991), the newt $N v H B o x-4$ and $N v H B o x-$ 5 genes (Beauchemin and Savard, 1992), and the Xenopus Xdll, $X$-dll $1, X$-dll2,$X$-dll3 and $X$-dll4 genes (Asano et al., 1992; Dirksen et al., 1993; Papalopulu and Kintner, 1993). Comparisons of the expression patterns of $d l \times 2, d l \times 3$, and $d l \times 4$ in zebrafish embryos indicate that distinct regions of the embryo express specific combinations of the three genes. We suggest that the distal-less genes could participate in a new type of homeobox gene codé during development.

\section{Materials and Methods}

Animals. Embryos from the Oregon $\mathrm{AB}$ line were maintained using standard methods (Westerfield, 1993) and were staged at $28.5^{\circ} \mathrm{C}$ according to hours (h) and days (d) postfertilization. 


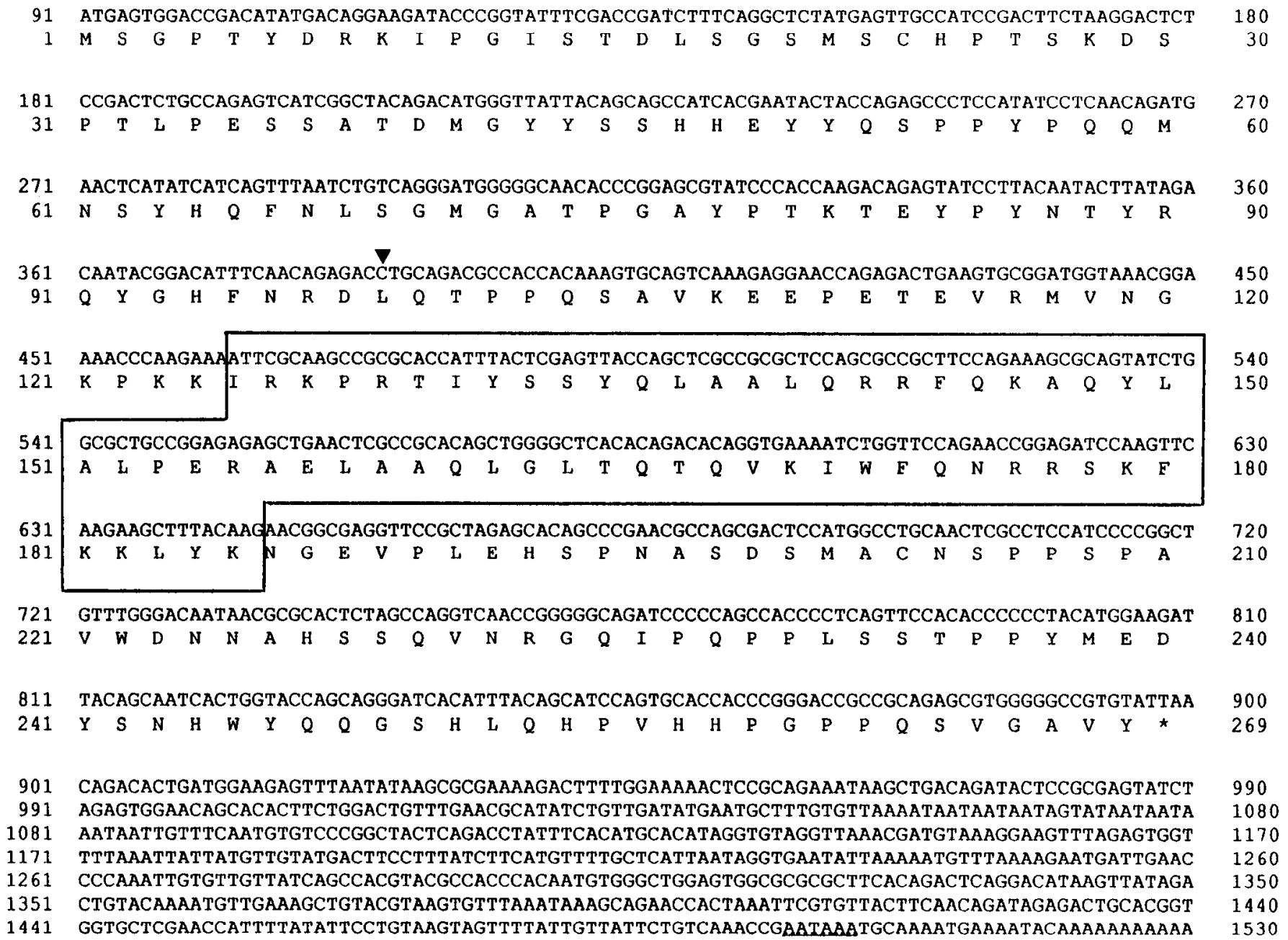

Figure 1. The nucleotide and the predicted amino acid sequences of the zebrafish $d l x 3$ gene. The homeodomain is boxed. The probe (see Materials and Methods) used for in situ hybridization was made from the sequences between nucleotide position 1 and the PstI site at position 385 (arrowhead). A potential polyadenylation site is underlined.

Isolation and sequencing of zebrafish $\mathrm{dl}$ x genes. Dlx3 was isolated during the screening of a lambda gt-11 cDNA library, prepared from 2 d zebrafish mRNA, with a probe that includes the entire homeobox sequence of the mouse Msx I (Hox-7) gene (Robert et al., 1989; Ekker et al., 1992a). $D l \times 2, d l x 4$, and additional $d l x 3$ cDNA clones were obtained by screening two Lambda ZAP II (Stratagene, San Diego, CA) cDNA libraries prepared from 9-16 $\mathrm{h}$ and $20-28 \mathrm{~h}$ zebrafish mRNA with a $150 \mathrm{bp}$ XhoI- HindIII restriction fragment of the $d l x_{3} \mathrm{cDNA}$ corresponding to ' 1 e 5 ' portion of the $d l \times 3$ homeobox. Restriction fragments of the cDNAs were isolated and subcloned into Bluescript phagemids (Stratagene, San Diego, CA). Single-strand templates were prepared from these phagemids according to the manufacturer's instructions. DNA sequencing was performed by the dideoxy-termination method using Sequenase (U.S. Biochemicals, Inc.), according to the manufacturer's directions. Sequences were analyzed with the GCG package and the cvolutionary trec was constructed using the Phylip package kindly provided by J. Felsenstein (U. of Washington).

In situ hybridization. Zebrafish embryos were fixed with paraformaldehyde and in situ hybridization was performed on whole-mount or sectioned embryos using antisense riboprobes as previously described (Ekker et al., 1992a; Püschel et al., 1992). The following DNA fragments were used as templates for the synthesis of antisense riboprobes: $d l x 2$, either the entire $1667 \mathrm{bp}$ cDNA or a $473 \mathrm{bp} E c 0$ RI fragment in which one EcoRI occurs at position 496 , the cloning site of a shorter cDNA clone, and the other at position 968 (Fig. 2); $d l x 3$, either the entire 1532 bp cDNA or a 390 bp EcoRI-PstI fragment in which the EcoRI site was the $5^{\prime}$ cloning site and the $P$ st I site was located at position 385 (Fig. 1); $d l x 4$, either the entire $1123 \mathrm{bp}$ cDNA, a $744 \mathrm{bp} P s i \mathrm{I}-E c o \mathrm{RI}$ fragment with the PstI site at position 136 and the EcoRI site at position 879 , or a 484 bp EcoRI-HinclI fragment from the 5' EcoRI clone site to the HincII site at position 484 (Fig. 3). In all cases, different probes from each gene produced identical expression patterns except that the intensity of the signal was strongest with the longest probe.

Despite the high degree of sequence similarity among the three $d l x$ genes and our use of at least part of the coding region, cross-hybridization among probes was minimal, as indicated by the unique features of each in situ hybridization pattern.

\section{Results}

Molecular cloning of three zebrafish homeobox genes related to distal-less

We isolated cDNAs that correspond to the transcripts of genes with homeoboxes related in sequence to the Drosophila distalless gene (Cohen et al., 1989; Vachon et al., 1992). We recovered the first of these genes, which we named $d l \times 3$ during a screen for zebrafish genes belonging to the $m s x$ family of homeobox genes (Akimenko et al., 1991; Ekker et al., 1992a). Southern analysis of zebrafish genomic DNA with a probe corresponding to the homeobox of $d l \times 3$ (not shown) suggested that the zebrafish 


\section{ACATCTGTCGTTGGACTTGCTTTTAAGTGTGCTTTTGCGGTATGAAAAACATGACTGGAGTTTTTGACAGCCTCAGTACAGATATGCATT}

CGAACCAGATTACCTCCAGCAGTTACCACAGTCTGCACAAGTCCCAGGAATCGCCGACTCTTCCGGTCTCCACCGCTACCGACAGCAGCA

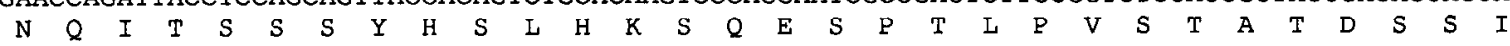

TCAATAATAATAACCAGCAGTGCGCTGGCTCTCCGTACGGCCAGAGCAGCTCTTATCAGTACCAGAACAACAGCATGAACAGCGTCCAGT $\begin{array}{llllllllllllllllllllllllllllllllll}N & N & N & N & Q & Q & C & A & G & S & P & Y & G & Q & S & S & S & Y & Q & Y & Q & N & N & S & M & N & S & V & Q & Y\end{array}$

ACAACACCAAATCATACGAGCTGGGCTTCGGAAACGCTTTCGGCCCCTACGGCACCTACGGCTCCTGCTCCTCACCAACTCCTGCAGATG $\begin{array}{llllllllllllllllllllllllllllll}N & T & K & S & Y & E & \text { L } & G & F & G & N & A & F & G & P & Y & G & T & Y & G & S & C & S & S & P & T & P & A & D & A\end{array}$ CTGAAAAGGAAGAAAGAGAACCTGAAATCCGAATGGTCAATGGAAAGCCAAAGAAATTCCGAAAACCTCGTACTATTTACTCGACTTTCC

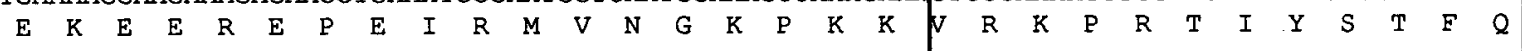
AGCTGGCGGCCCTGCAGAGGAGGTTTCAGAAGACTCAGTATCTGGCCTTGCCGGAGAGAGCTGAGCTGGCCGCATCTCTGGGCCTCACGC $\begin{array}{lllllllllllllllllllllllllllllll}\text { L } & A & A & \text { L } & Q & R & \text { R } & \text { F } & Q & \text { K } & \text { T } & Q & \text { Y } & \text { L } & \text { A } & \text { L } & \text { P } & \text { E } & \text { R } & \text { A } & \text { E } & \text { L } & \text { A } & \text { A } & \text { S } & \text { L } & G & \text { L } & \text { T } & Q\end{array}$ AAACACAGGTTAAAATCTGGTTCCAGAATCGTCGTTCAAAGTTCAAGAAGTTGTGGAAA AGTGGAGAGATCCCACCCGAGCAGCA'TGI'GG $\begin{array}{llllllllllllllllllllllllllllll}T & Q & V & K & I & W & F & Q & N & R & R & S & K & F & K & K & L & W & K & S & G & E & I & P & P & E & Q & H & V & A\end{array}$ CCTCCGGTGAGTCTCCACCTCACCCCTCACCTCCTCTCGCCGCGGCCTGGGACTTCGCGCACAGCCAGAGAATGAACACTGTAAACTCGG $\begin{array}{lllllllllllllllllllllllllllllllll}S & G & E & S & P & P & H & P & S & P & P & I & A & A & A & W & D & F & A & H & S & Q & R & M & N & T & V & N & S & G\end{array}$

GTTTGTCGCAGAGCAGCCCTCCTAACTCAACCACCCCTTCCTTTCTGACAAACTACCCCTGGTATTCATCCACGAACTCTGCGGCCCACC $\begin{array}{lllllllllllllllllllllllllllllll}\mathrm{L} & \mathrm{S} & \mathrm{Q} & \mathrm{S} & \mathrm{S} & \mathrm{P} & \mathrm{P} & \mathrm{N} & \mathrm{S} & \mathrm{T} & \mathrm{T} & \mathrm{P} & \mathrm{S} & \mathrm{F} & \mathrm{L} & \mathrm{T} & \mathbf{N} & \mathrm{Y} & \mathrm{P} & \mathrm{W} & \mathrm{Y} & \mathrm{S} & \mathrm{S} & \mathrm{T} & \mathrm{N} & \mathrm{S} & \mathrm{A} & \mathrm{A} & \mathrm{H} & \mathrm{L}\end{array}$ TTCAGCCACCACTTCATCACAATACAACTGTTAGCGCCGGGACCATATTTTGACTCGGCCGCTTGCGGAATTCAGTTTGTGAACTGAACT

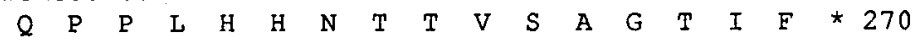

TAAATGACTTTTAGGCCTGTTTGGCAGTCTTGGTGAGACCTCGATCTGCACCGATGCCACGTTGATCATTGCCAGTGCGATTTGGGCGTG ACACTGTTACTTTTCATGCAATGTCGCGTCACGAAGCAGACACTACAGAATCAAACATATACAATTATTTTTGTATTTATTTATTTTGTT CTATGAGTGGTACGTCTATGGATTAAAGTGAACTACAATTATCCAAAGCCTAGAGAACTCATGTGGACATTATTGGAGTAAATATTTGCA GCAGGGT GAATCAGAGCACATGTAGCACAACCTGAAGCTGTTTGGTGCCTTCTTGAAAATAACCTGACTTGTCGGTTTCCATGTGTTTCA TGCGCCTGTCTTTACTTTCAGATTTGTTTTTGTTCATTTATATTTAGTAGCCTATACGCAAGGTAAGTTGGAAATTTGGTGTCCGTCTTG TATGTGTCCCATCGCGTCTATTTAATAAGTTGTTATTCGTATAGATATCATAAGAGTTTCACTGTTTAAACACTAATGAAAATCACACGC AAGCTACTGATTGTCCTAAAGTCATGTATATTTTTTTCTGGAGTTCTTTGTTTTATTTATTTTGAAAGCCGAATGAACATCTCTGCCACT ATAATGATTCAGACTATTTAAATAAAATGTTTCATGTGAAAAAAAA 1667

Figure 2. The nucleotide and the predicted amino acid sequences of the zebrafish $d l x 2$ gene. The homeodomain is boxed. The probe used for in situ hybridization was made from the sequences between nucleotide position 496 ( $5^{\prime}$ end of a shorter cDNA clone) and the EcoRI site at position 968 (arrowheads). A potential polyadenylation site is underlined. The sequence accession number for $d l x 2$ is U03875.

genome might contain additional genes with related homeoboxes. We therefore screened embryonic cDNA libraries and obtained clones corresponding to two additional $d l x$ genes, $d l x 2$ and $d l x 4$, and several more $d l x 3$ cDNA clones.

The longest $d l \times 3 \mathrm{cDNA}$ clone, with $1532 \mathrm{bp}$, contains an open reading frame of $843 \mathrm{bp}$ (Fig. 1). Several potential ATG initiation codons are located near the $5^{\prime}$ end of the open reading frame; the ATG at position 91 is the last ATG in the $5^{\prime}$ direction before an in-frame stop codon and the only ATG upstream from a region that is well conserved at the amino acid level between $d l \times 3$ and a related newt gene (see below). If used as the starting codon, this ATG would initiate translation of a 269 amino acid protein. A polyadenylation site occurs at positions 1498-1503.

We isolated three cDNAs corresponding to the $d l x 2$ gene. The longest of these cDNAs (1667 bp; Fig. 2) contains an open reading frame of $834 \mathrm{bp}$. Two ATG initiation codons are present in the $5^{\prime}$ end of the open reading frame. Use of the more upstream ATG would produce a protein of $273 \mathrm{AA}$ and use of the next ATG would encode a protein with a predicted size of 270 AA. Amino acid sequence comparisons with the product of the mouse $D l \times 2$ gene (not shown) suggest that the amino terminus of the protein is conserved between fish and mice and that the second ATG serves as the initiation codon. A polyadenylation site is found at positions 1641 to 1646 .
We isolated three cDNAs corresponding to the $d l x 4$ gene. The longest is $1123 \mathrm{bp}$ (Fig. 3) and the largest open reading frame within this cDNA is $906 \mathrm{bp}$. Using the ATG initiation codon nearest to the $5^{\prime}$ end of this long open reading frame predicts a protein of $283 \mathrm{AA}$.

The predicted homeodomains of $d l x 2, d l x 3$, and $d l \times 4$ (Fig. $4 A$ ) closely resemble those of the mouse $D l x 1$ and $D l x 2$ (Tes1) genes (Porteus et al., 1991; Robinson et al., 1991), the newt $N v H B o x-4$ and $N v H B o x-5$ genes (Beauchemin and Savard, 1992), and the Xenopus $X$-dll1-4 gene (Asano et al., 1992; Dirksen et al., 1993; Papalopulu and Kintner, 1993).

The zebrafish Dlx proteins are related to each other and to Dlx proteins from other species

The homeodomains of the three zebrafish Dlx proteins are identical at 51 positions $(84 \%)$ and the three proteins are $80 \%$ identical over a stretch of $85 \mathrm{AA}$ that includes the $17 \mathrm{AA}$ residues that precede the homeodomain, the homeodomain itself, and the $7 \mathrm{AA}$ that follow it (Fig. $4 A$ ). One additional region of high similarity is found in a 19 AA stretch near the amino terminal of the predicted proteins (Fig. $4 B$ ), where the three proteins are $53 \%$ identical. Interestingly, a similar sequence is found in the mouse Dlx2 (Tes-1) (Porteus et al., 1991; Robinson et al., 1991), the newt $N v H B o x-4$ (Beauchemin and Savard, 1992), and the 
91

AACTATGACTGGAGTATTCGACAGAAGGATTCCGAGTATTAAACCTGCAGATTTTCAAAACCCTTTTCAGCTCTCCACGATGCATCATCC $\begin{array}{lllllllllllllllllllllllllllllll}M & T & G & V & F & D & R & R & I & P & S & I & K & P & A & D & F & Q & N & P & F & Q & L & S & T & M & H & H & P\end{array}$

GTCTCAGGAATCTCCAACCCTACCGGAGTCCACAGCCACGGATTCTGGCTATTACAGCCCTGCTGGAGGAGT'TCATCATGGCTATTGTTC $\begin{array}{lllllllllllllllllllllllllllllllll}S & Q & E & S & P & T & L & P & E & S & T & A & T & D & S & G & Y & Y & S & P & A & G & G & V & H & H & G & Y & C & S\end{array}$

ACCGAACTCGGGCACCTATGGGAAACTCTTAATGCCTATCAGTACCAATACCACGGAGTCAATGGATCTTCTGGAAATTACTCTGCAAA $\begin{array}{lllllllllllllllllllllllllllllll}\mathbf{P} & \cdot & \mathbf{N} & \mathbf{S} & \mathbf{G} & \mathbf{T} & \mathbf{Y} & \mathbf{G} & \mathbf{K} & \mathbf{P} & \mathbf{L} & \mathbf{N} & \mathbf{A} & \mathbf{Y} & \mathbf{Q} & \mathbf{Y} & \mathbf{Q} & \mathbf{Y} & \mathbf{H} & \mathbf{G} & \mathbf{V} & \mathbf{N} & \mathbf{G} & \mathbf{S} & \mathbf{S} & \mathbf{G} & \mathbf{N} & \mathbf{Y} & \mathbf{S} & \mathbf{A} & \mathbf{K}\end{array}$

\section{ATCCTACCCTGATTACGGCTCATACTCCACAGCGTATCACCAATACGCAGGAACATATAACAGAGTGCAATCACAACCGAGCCCGCAAGA} $\begin{array}{llllllllllllllllllllllllllllllll}S & Y & P & D & Y & G & S & Y & S & T & A & Y & H & Q & Y & A & G & T & Y & N & R & V & Q & S & Q & P & S & P & Q & E\end{array}$

AAAAGAAACAGCCGAGCCCGAAGTAAGGATGGTCAACGGAAAACCCAAAAAAGTCCGGAAGCCCCGAACCATTTACTCCAGTTTCCAGCT

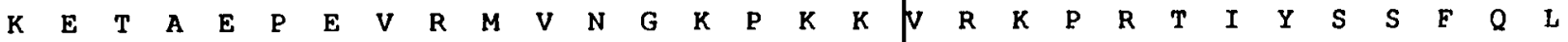
CGCAGCTTTACAGAGAAGGTTTCAGAACACGCAATACCTCGCGCTTCCAGAAAGAGCCGAGCTCGCCGCATCGCTGGGACTCACACAGAC

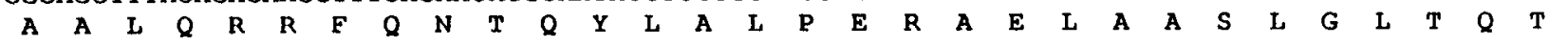
ACAGGTGAAAATCTGGTTCCAGAACAAAAGATCAAAACTAAAGAAGATTATGAAA AACGGCGAACTGCCCCCAGAACACAGCCCCAGCTC $\begin{array}{llllllllllllllllllllllllllllll}Q & V & K & I & W & F & Q & N & K & R & S & K & L & K & K & I & M & K & N & G & E & L & P & P & E & H & S & P & S & S\end{array}$ CAGCGACCCAATGGCGTGTAACTCACCGCAGTCTCCCGCGGTCTGGGACTCACAGGGTCCTCAGAGACCTCACCATCAGCCGCAAAATAT

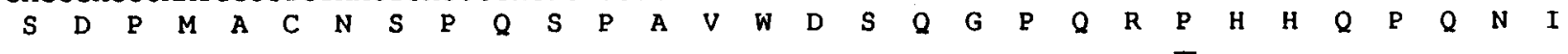
TAACACAGCGGCATCCACGTTTCTGGAAATGCGCGAGCTCTTCGTGGTATTCCTCTACCGGGGCGATGAATTCTTCACCCTTCAGGCACC $\begin{array}{lllllllllllllllllllllllllllllll}\mathbf{N} & \mathbf{T} & \mathbf{A} & \mathbf{A} & \mathbf{S} & \mathbf{T} & \mathbf{F} & \mathrm{L} & \mathbf{E} & \mathbf{M} & \mathbf{R} & \mathbf{E} & \mathbf{L} & \mathbf{F} & \mathbf{V} & \mathbf{V} & \mathbf{F} & \mathrm{L} & \mathbf{Y} & \mathbf{R} & \mathbf{G} & \mathrm{D} & \mathbf{E} & \mathbf{F} & \mathbf{F} & \mathbf{T} & \mathbf{L} & \mathbf{Q} & \mathbf{A} & \mathbf{P}\end{array}$

\section{CGGCACGTTACACTCGTTGGCACTCGGATCAGGAACGTTGTACTGAAAATTGTTTATTATTTTTGTTGTATATTGGACTGGTTGTTAACA}

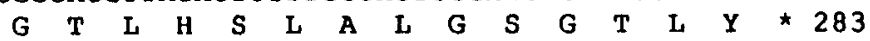

Figure 3. The nucleotide and the predicted amino acid sequences of the zebrafish $d l x 4$ gene. The homeodomain is boxed. The probe used for in situ hybridization was made from the sequences between the PstI site at position 136 and the EcoRI site at position 879 (arrowheads). The sequence accession number for $d l \times 4$ is $\mathrm{U} 03876$.

Xenopus $X$-dll1, $X$-dll2, $X$-dll3, and $X$-dll4 (Dirksen et al., 1993; Papalopulu and Kintner, 1993) genes, but not in the newt NvHBox-5 (Beauchemin and Savard, 1992), the mouse Dlxl (personal communication from J. L. R. Rubenstein), or the Xenopus $X$-dll (Asano et al., 1992) genes. Several interspersed amino acid residues are also well conserved among vertebrate distal-less proteins for which this information is available. Examples include the $Q$ residue at AA position 65 in Figure 1, the $Y$ at position 92 , a WD sequence at positions $222-223$, the LQXP sequence at positions 252-255, and the G located four residues before the stop codon (Fig. 1).

The vertebrate dlx genes can be subdivided into four orthologous groups

We performed pairwise and multiple alignments of the predicted protein sequences of the zebrafish and other vertebrate $d l x$ genes. From the results of pairwise alignments we built an evolutionary tree that divides the vertebrate $d l x$ genes into four orthologous groups (Fig. 5), with each of the zebrafish $d l x 2, d l \times 3$, and $d l x 4$ genes belonging to a different group.

The product of the zebrafish $d l \times 2$ gene shows extensive similarity to that of the mouse Dlx2 (Tes-1) and the Xenopus $X$-dll4 and $X$-dll 1 genes, both within and outside the homeodomain $(97 \%, 95 \%$, and $95 \%$ identity in the homeodomain, and $69 \%$, $67 \%$, and $67 \%$ overall identity, respectively). On the basis of this sequence analysis, we named this zebrafish gene $d l x 2$. The homeodomain encoded by $d l x 3$ is identical to that of the newt
$N v H B O x-4$ gene product and nearly identical to that of $X$-dll2, with only one substitution (Fig. $4 A$ ). The sequences outside the homeodomain are also very similar, $72 \%$ and $65 \%$ identity, respectively. Therefore, $d l x 3, N v H B o x-4$, and $X$-dll 2 could be the zebrafish, newt, and Xenopus versions of the same gene. The zebrafish Dlx4 protein shows particular sequence similarity only with the predicted product of $X$-dll3 (72\% identity).

Division of vertebrate distal-less genes into subfamilies was recently proposed on the basis of the sequence similarities of their homeodomains (Papalopulu and Kintner, 1993). According to this classification, the $X d l l-3$ and $X d l l-4$ genes belong to a single subfamily, while our analysis suggests that they belong to two different orthologous groups. Comparisons of complete protein sequences are more likely to reveal differences and similarities than comparisons of homeodomain sequences alone because of the high degree of sequence conservation in the homeodomain, even though there is somewhat greater conservation of the predicted homeodomains among members of a given orthologous group (Fig. $4 A$ ). Conservation of the 19 AA sequence found in the amino terminal regions of the proteins is also consistent with this division of the genes into four orthologous groups (Fig. 4B). Our analysis further suggests that the fourth group, which includes the mouse $D l x 1$, the newt $N v$ $H B o x-5$, and the Xenopus Xdll genes, may also contain a possible fourth and as yet unidentified zebrafish distal-less-related gene.

Mouse homeobox sequences named $D l x 3$ and $D l \times 4$ were pre- 
A

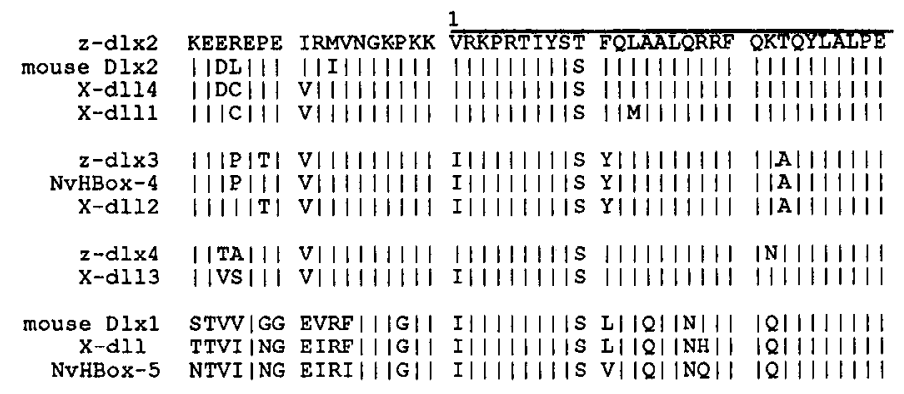

B

z-dlX2 RAELAASLGL TQTQVKIWFQ NRRSKEKKLWK SGEIPPEQH

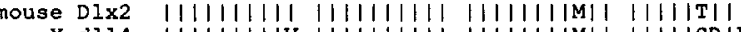

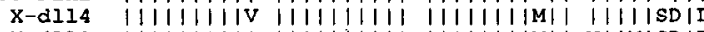

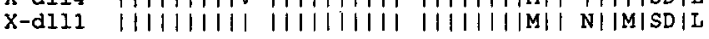

$z-d l \times 3 \quad|||||| Q|\|||||||||||||||||||| Y \mid$ N||V|.LE

NvHBOX-4 ||||||$Q||||||||||||||||||||||$ Y N||V|GME

$\mathrm{X}-\mathrm{dll2}|||||| Q|\|||||||||||||||||||I Y| N|| G|G L E|$

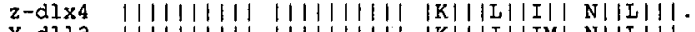

mouse DIX1 $|\|\|\|\|\|\||\||\|\|\|\|\|\|\|\|\|\|| M \mid$ Q|GALIGS

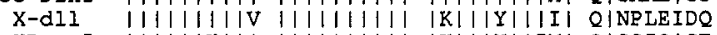

NvHBOX-5 |||||H||| ||||||||| |K|||Y||IM| Q|SSIQ|GE

$z$-dlX4 SQESPTLPES TATDSGYYS

$\mathrm{X}-\mathrm{d} 113$ ||D||||||| |||||||| $\mid$

z-dlx2 $|1||1||| \mathrm{V}||||||$ SINN

mouse Dlx2 Pl|l|||V| IIIIISIIT

$\mathrm{X}-\mathrm{dlll} 4$ lil||||V| |l|l|s|l

$\mathrm{X}$-dili lil|l||V| |||||s||T

$z-d 1 \times 3 \quad|K D||||||| S|||M||| \mid$

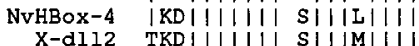

Figure 4. Sequences of conserved regions in vertebrate Dlx proteins. The amino acid sequences of the homeodomain and surrounding amino acids $(A)$ and of a region near the N-terminus $(B)$ of the three zebrafish Dlx predicted proteins are aligned with the products of related vertebrate genes. Identities are indicated by vertical bars. Gaps are indicated by dots. The homeodomain in $A$ is indicated with a horizontal bar. The sources for the sequences are, for mouse $d l \times 2$, Porteus et al. (1991), Robinson et al. (1991); Xenopus X-dll1, Dirksen et al. (1993); X-dll, Asano et al. (1992); $X$-dll2, $X$-dll3, and $X$-dll4, Papalopulu and Kintner, (1993); and newt $N v H B o x-4$ and $N v H B o x-5$, Beauchemin and Savard (1992). The mouse $D l x-1$ sequence is a personal communication from J. L. R. Rubenstein.

viously reported (Robinson et al., 1991) and the presence of a mouse $D l x 3$ gene was also suggested by Dollé et al. (1992). However, in the former report, only the homeobox sequences are given, and in the latter report, no sequence information is available. Therefore, considering the high degree of sequence similarity among distal-less homeoboxes, it is not yet possible, only on the basis of homeobox sequence comparisons, to determine in which orthologous group these two mouse genes belong.

\section{Expression of the dlx genes in zebrafish embryos}

Gastrulation and the olfactory and auditory placodes. Expression of the $d l x$ genes begins with $d l x 3$ during late gastrula stages. By $8 \mathrm{~h}$ (hours postfertilization) scattered cells on the ventral side of the embryo express detectable levels of $d l x 3$ transcripts. Within an hour, expressing cells coalesce into a stripe that extends around the lateral edge of the embryo, midway between dorsal and ventral, and which is shaped like the stitches on a baseball (Fig. 6A). Along its anterior half, the stripe is approximately six

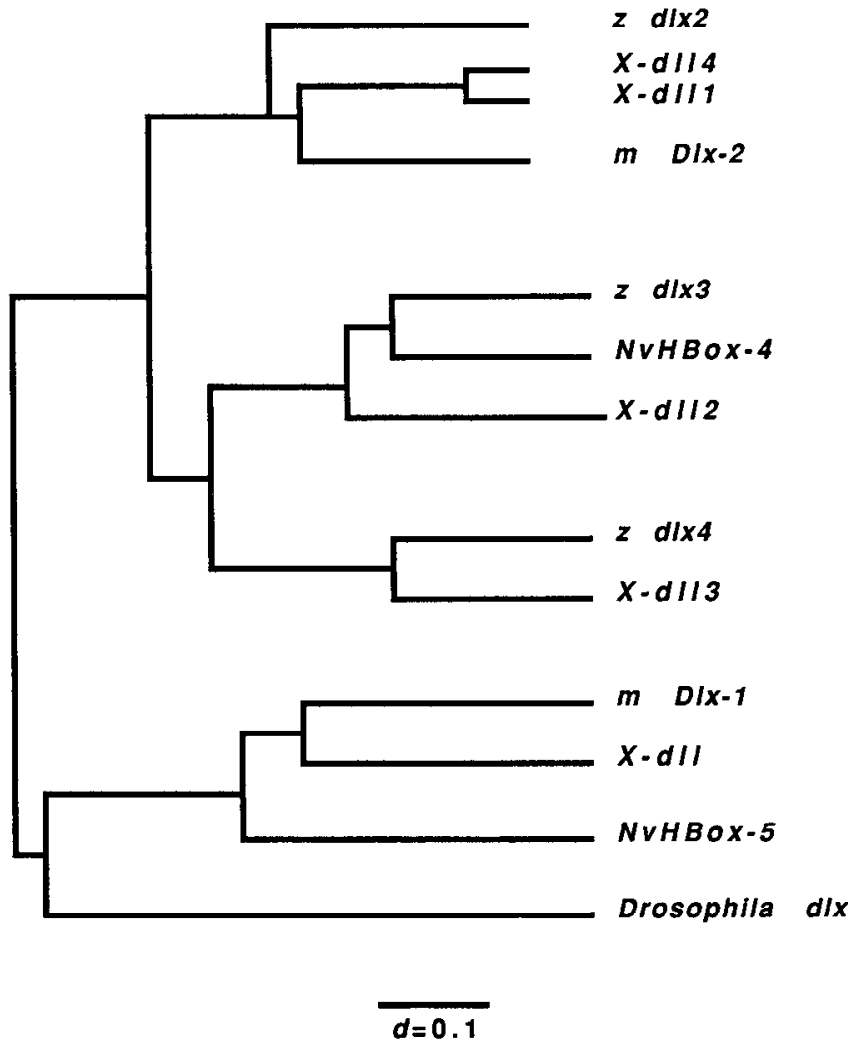

Figure 5. Dlx genes form four orthologous groups: evolutionary tree for 13 distal-less-related homeobox genes. The same nomenclature was used as for Figure 4. The tree was made from a distance matrix using the neighbor joining method (Saitou and Nei, 1987). The distance matrix was calculated from amino acid sequnce identity values. A tree predicting the same relationships among the genes was obtained using amino acid sequence similarity values. The scale bar indicates the estimated evolutionary distance.

cells wide and includes presumptive ectodermal cells (Fig. $6 D$ ). Posteriorly, the stripe broadens and the scattered expressing cells are separated from one another by nonexpressing cells (Fig. $6 \mathrm{~A}$ ). During gastrulation, the lateral parts of the stripe converge toward the dorsal midline (Fig. $6 \mathrm{~B}$ ), probably due to convergence of the $d l \times 3$-expressing cells.

By the end of gastrulation, the lateral regions of the $d l \times 3$ stripe have reached the edge of the developing neural keel and expression is progressively restricted to two patches on each side that later form the olfactory and auditory (Ekker et al., 1992a) placodes and a patch at the posterior end of the embryo that may contribute to the tail bud (Fig. $6 \mathrm{C}$ ). The formation of these patches is probably due to downregulation of $d l \times 3$ expression by cells in intervening regions of the stripe, rather than to migration of expressing cells into the patches, because there is no ubvious increase in the numbers of expressing cells in the regions of the patches and because convergence of cells during gastrulation is accompanied by extension rather than contraction along the dorsal midline (Warga and Kimmel, 1990). Beginning around $24 \mathrm{~h}$ and continuing until about $48 \mathrm{~h}$, cells of the olfactory placodes also weakly express $d l x 4$.

Cranial neural crest. Presumptive neural crest cells in the head express $d l x_{2}$ beginning around $12 \mathrm{~h}$. Initially, cells scattered over the dorsal surface of the hindbrain express $d l x 2$ in a pattern that shows no obvious segmental organization (Fig. 7A). By 13 $\mathrm{h}$, the positive cells, which can then be recognized as neural 

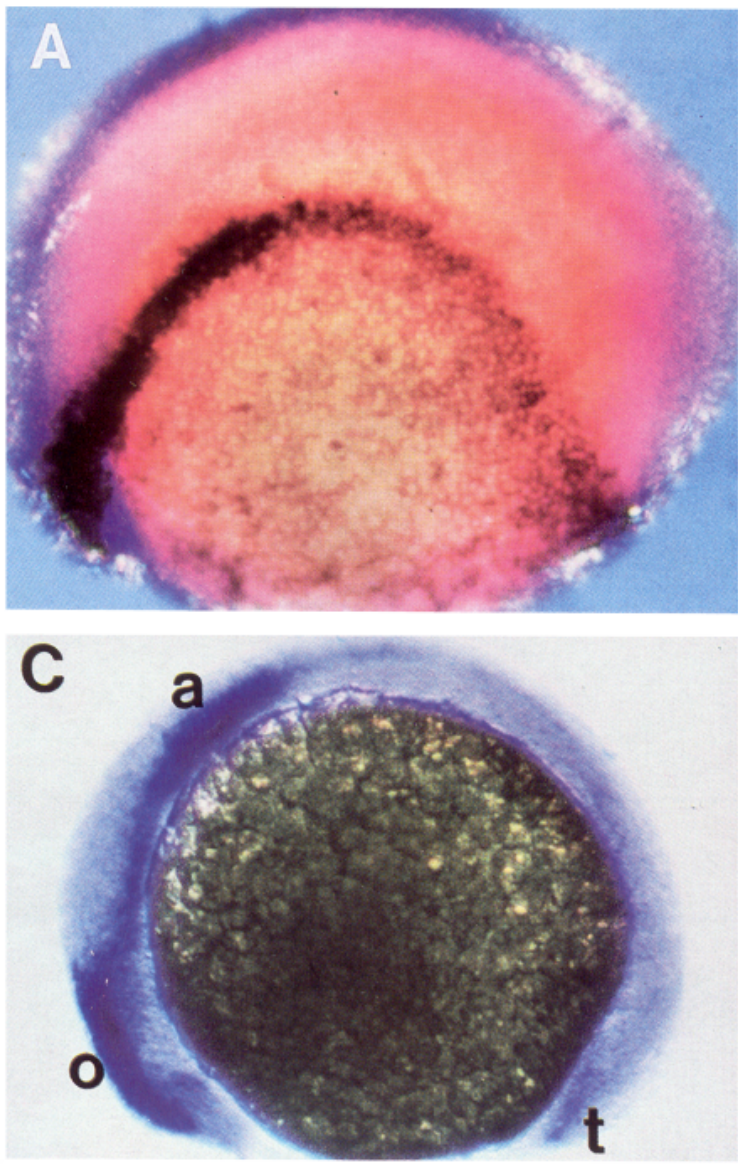
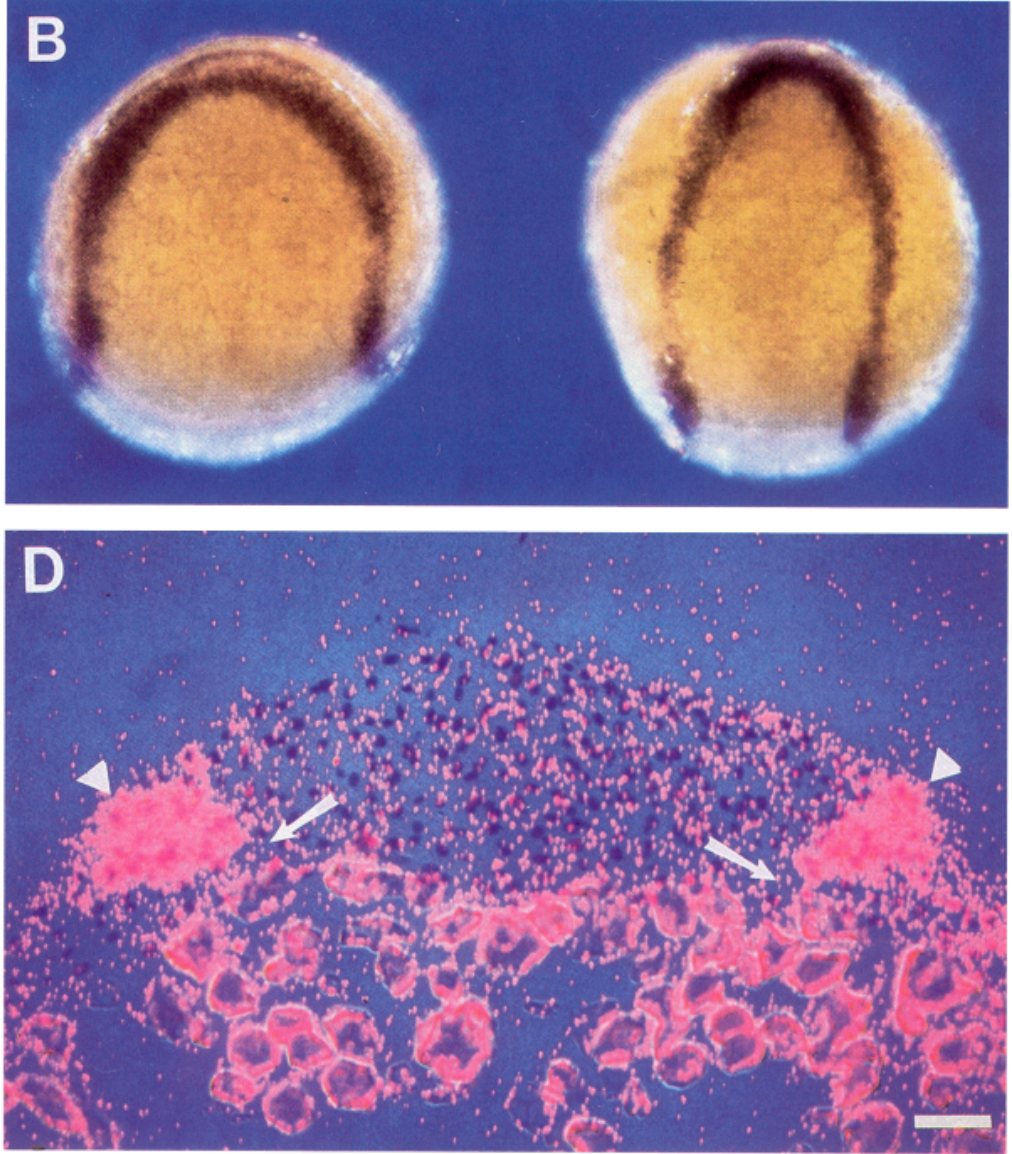

Figure 6. Ectodermal cells of the gastrula express $d l x 3$ transcripts: in situ hybridization of whole-mount embryos with a $d l x 3$ probe. $A$, At 9 h, scattered cells on the ventral surface of the embryo and a denser stripe of cells around the lateral edge of the presumptive neural plate express $d l x 3$. $B$, The lateral regions of the stripe of $d l x 3$-expressing cells rapidly converge toward the dorsal axis shown in $9.5 \mathrm{~h}(l e f t)$ and $10.25 \mathrm{~h}($ right $)$ embryos. $C$, Expression becomes progressively restricted and includes precursors of the olfactory $(o)$ and auditory $(a)$ placodes and the tailbud $(t)$ shown here at $12 \mathrm{~h}$. $D$, Superficial cells express $d l x 3$, shown here in a cross section through the anterior region of a $10 \mathrm{~h}$ embryo. The $d l x 3$ signal appears as red grains in this autoradiograph. The red at the bottom is produced by the yolk granules and is not due to specific hybridization as revealed by examination of nonhybridized sections. The arrows indicate unlabeled, presumptive mesodermal cells. Anterior to the left and dorsal to the top in $A$ and $C$; dorsal midline view looking down on animal pole in $B$ with anterior to the top; dorsal is up $D$. Scale bar: $60 \mu \mathrm{m}$ for $A$, $100 \mu \mathrm{m}$ for $B, 85 \mu \mathrm{m}$ for $C, 40 \mu \mathrm{m}$ for $D$.

crest cells by their morphologies and positions (Schilling, 1993), appear in a distinct segmental pattern as they seem to migrate into the periphery along pathways adjacent to rhombomeres 1 , 2,4 , and 6 (Fig. $7 B$ ). Expression of $d l x 2$ persists in the migrating crest cells as they reach and enter the primordia of the branchial arches (Fig. 7C).

Forebrain. By $13 \mathrm{~h}$, cells of the presumptive forebrain express $d l x 2$ and $d l x 4$. During the first day of development (Fig. 8A), the expression patterns of the two genes are similar, with positive cells in the presumptive telencephalic and diencephalic bands
(Wilson et al., 1990). These bands probably correspond to the two domains of distal-less expression in the forebrain of mouse (Dlxl and Dlx2; Bulfone et al., 1993b) and Xenopus (X-dll3 and $X$-dll4; Papalopulu and Kintner, 1993). During subsequent development, divergence of the zebrafish $d l \times 2$ and $d l \times 4$ patterns becomes more apparent as overlapping but distinct sets of forebrain cells express the two genes (Figs. $8 B, C ; 9 A, C$ ). In the telencephalon, cells expressing $d l x 2$ are located medially (Figs. $8 B, 9 A$ ) close to the ventricular surface, whereas $d l x 4$-expressing cells appear as bilateral bands located more superficially (Figs.

Figure 7. Cells of the cranial neural crest and precursors of the branchial arches express the $d l x 2$ gene. $A$, Presumptive neural crest cells along the dorsal and dorsal lateral sides of the hindbrain express $d l \times 2$ at $12 \mathrm{~h}$. B, Neural crest cells migrating from the hindbrain rhombomeres of a 13 $\mathrm{h}$ embryo express $d l x 2$ while hindbrain cells in rhombomeres 3 and 5 (arrowheads) express krx20 (Oxtoby and Jowett, 1993). C, Cells in the mandibular $(m)$, hyoid $(h)$, and first through third gill arches $(1-3)$ express $d l x 2$, shown here at $24 \mathrm{~h} . D$, Mesenchymal cells in the arches express $d l \times 2$, whereas cells of the pharyngeal endoderm lining the arches do not (indicated here at $48 \mathrm{~h}$ and in $C$ by arrows). Anterior is to the left and dorsal to the top; lateral views in $A, C$, and $D$; dorsal view in $B$. Scale bar, $60 \mu \mathrm{m}$ for $A$ and $B, 25 \mu \mathrm{m}$ for $C, 16 \mu \mathrm{m}$ for $D$.

Figure 8. Overlapping but distinct sets of forebrain cells express $d l \times 2$ and $d l x 4$. A, Side view of head of whole-mount embryo at $24 \mathrm{~h}$ hybridized with $d l x_{2}$ probe. $B$ and $C$, Approximately horizontal sections through heads of $27 \mathrm{~h}$ embryos hybridized with $d l x 2(B)$ or $d l x 4(C)$ probes and counterstained with basic fuchsin. The arrows in $A$ and $C$ indicate expression in the line of cells that extends through the presumptive hypothalamus. $t$, telencephalic band; $d$, diencephalic band; $e$, eye. Scale bar, $25 \mu \mathrm{m}$. 

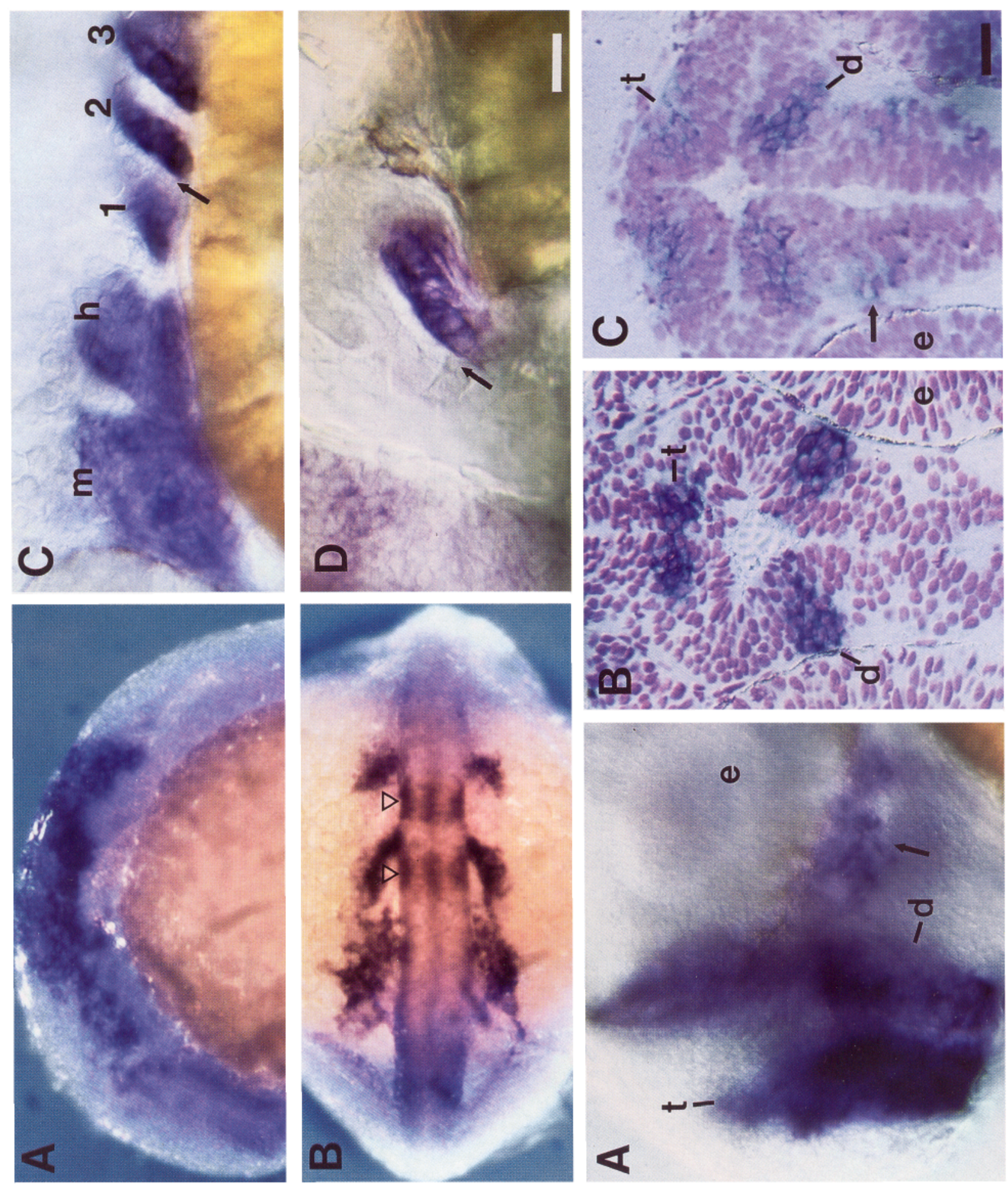
Table 1. Summary of expression patterns of three zebrafish $d l x$ genes

\begin{tabular}{lllll} 
& $16 \mathrm{~h}$ & $24 \mathrm{~h}$ & $48 \mathrm{~h}$ & $\begin{array}{l}55-60 \\
\mathrm{~h}\end{array}$ \\
\hline Telencephalon & $2-4$ & $2-4$ & $2-4$ & $2-4$ \\
$\begin{array}{l}\text { Diencephalon } \\
\text { Olfactory placodes and }\end{array}$ & $2-4$ & $2-4$ & $2-4$ & $2-4$ \\
$\quad$ precursor cells & & & & \\
Migrating neural crest & $-3-$ & -34 & -34 & $-3-$ \\
Pectoral girdle & $2--$ & --- & --- & --- \\
Otic placode and vesicle & --- & $-3-$ & $-3-$ & $-3-$ \\
Sensory maculae & $-3-$ & -34 & -34 & --4 \\
Pectoral fin bud & --- & --- & $2-4$ & $2-4$ \\
Median fin fold & $2--$ & $2--$ & 234 & 234 \\
Visceral arches & -34 & 234 & --- & --- \\
$\quad$ Mandibular & & & & \\
$\quad$ Hyoid & $2--$ & 234 & $23-$ & $23-$ \\
$\quad$ Gill arch 1 & $2--$ & 234 & 234 & 234 \\
$\quad$ Gill arch 2 & $2--$ & $2-4$ & -34 & -34 \\
$\quad$ Gill arch 3 & $2--$ & 234 & 234 & -34 \\
$\quad$ Gill arch 4 & $2--$ & $2--$ & 234 & 234 \\
\hline
\end{tabular}

Expression of $d l \times 2$ (2), $d l \times 3$ (3), or $d l \times 4$ (4) was detected by in situ hybridization in structures, as listed at the left, at the times listed at the top. The - symbol indicates undetectable levels of expression.

$8 C, 9 C)$, corresponding very well to the expression patterns of the Xenopus $X$-dll 4 and $X$-dll3 genes, respectively (Papalopulu and Kintner, 1993). The expression patterns of the two zebrafish genes are similar in the diencephalon (Fig. 8B,C), and as in Xenopus, include bilateral punctate lines of expressing cells that extend from the diencephalic bands through the presumptive hypothalamus (Fig. $8 A, C$, arrows).

Branchial arches and pectoral girdle. Cells of the branchial arches express the three $d l x$ genes with different time courses. Of the three genes, $d l \times 2$ is expressed first, appearing in all the arch primordia by $16 \mathrm{~h}$, a time consistent with the arrival of the dlx2-expressing hindbrain neural crest cells (Schilling, 1993). By $24 \mathrm{~h}$, cells in the mandibular, hyoid, and second gill arch primordia express all three genes, whereas the primordium of the first gill arch expresses only $d l \times 2$ and $d l \times 4$, and the primordia of the posterior arches express only $d l x 2$ (Fig. $7 C$ ). By $36 \mathrm{~h}$, cells in all the arches express all three genes (Table 1), but by $48 \mathrm{~h}, d l \times 4$ expression disappears from the mandibular arch (Fig. $9 C$ ) followed by a rostral-to-caudal loss of $d l x 2$ expression from the gill arches (Table 1). Cells in all the gill arches still express the $d l \times 3$ and $d l \times 4$ genes at $55 \mathrm{~h}$. In each gill arch, expression of all three $d l x$ genes appears in the lateral, mesenchymal cells but is absent from the medial, endodermal cells (Fig. 7C,D).

Beginning at $24 \mathrm{~h}$, an accumulation of cells posterior to the last gill arch primordium expresses $d l \times 3$, but not $d l \times 2$ or $d l \times 4$ transcripts. During subsequent development, this expression domain extends posteriorly and includes precursor cells of the presumptive pectoral girdle (not shown).

Auditory vesicle. Cells oriented along the future axes of the auditory vesicle express $d l x 3$ and $d l \times 4$, but not $d l \times 2$ (Fig. $9 D$ $F$ ). By $24 \mathrm{~h}$, cells on the medial and caudal surface of the vesicle express $d l \times 3$ (Fig. 9E). The ventral edge of this expression domain is aligned with one of the future axes of the semicircular canals, as we have described previously (Ekker et al., 1992a). At this stage, cells on the medial and anterior surface of the vesicle express $d l x 4$. The ventral edge of this $d l x 4$ expression domain is oriented obliquely to the ventral edge of the $d l x 3$ domain (Fig. $9 F$ ) and may also be related to the future axes of the inner ear.

As the sensory maculae differentiate from the epithelium of the auditory vesicle, cells in the region of the maculae begin to express the $d l x 2$ and $d l x 4$ genes, but not $d l \times 3$ (not shown). Expression is apparent by $48 \mathrm{~h}$, a time when the sensory hair cells express the $m s x C$ and $m s x D$ genes (Ekker et al., 1992a).

Fins. Subsets of cells in the pectoral fin buds (Fig. $9 G-I$ ) and in the median fin fold (Fig. 10B) express the three $d l x$ genes in distinct patterns. By $16 \mathrm{~h}$, bilateral crescents of cells express the $d l x 2$ gene in the presumptive pectoral fin buds over the yolk lateral to the anterior somites. During the following several hours of development, these cells rise up off the surface of the yolk as other cells coalesce beneath them to form the pectoral fin buds by about $28 \mathrm{~h}$. The crescent is located at the distal edge of the fin bud and is equivalent to the apical ectodermal ridge (AER) of other vertebrates (Wood, 1982). After the first day of development, expression of the $d l \times 3$ and $d l \times 4$ genes begins in the AER. Cells in the most anterior region of the AER express $d l x 3$ (Fig. 9H) and $d l x 4$ (Fig. 9I), whereas cells in the most posterior region express $d l \times 2$ (Fig. $9 G$ ) and $d l \times 3$ (Fig. $9 H$ ). By $55 \mathrm{~h}$, expression of all three $d l x$ genes is confined to mesenchymal cells in the tip of the extending pectoral fin (Fig. 10A).

In the tailbud, a stripe of midline cells expresses the $d l x$ genes at $16 \mathrm{~h}$ (not shown). These cells include superficial epithelial cells along the length of the tail and deeper mesenchymal cells in the tail bud. The superficial cells probably contribute to the median fin fold.

At this stage, the expression of $d l \times 3$ and $d l \times 4$ in superficial cells is uniform around the tail bud, whereas $d l x 2$ expression is restricted to a subset of cells on the ventral surface. At $24 \mathrm{~h}$ (Fig. 10B), cells of the median fin fold express all three genes although $d l \times 2$ expression appears to be weaker than that of $d l x 3$ and $d l x 4$. At later stages, expression of the $d l x$ genes becomes restricted to the caudal fin primordium.

\section{Discussion}

Four orthologous groups of $\mathrm{dlx}$ genes

We identified three zebrafish homeobox-containing genes, $d l x 2$, $d l x 3$, and $d l x 4$. On the basis of the predicted amino acid sequences of their homeodomains, the three genes belong to the distal-less family. In addition to the homeodomain and the amino acid residues that surround it, the sequences of the DLX2, DLX 3 , and DLX 4 proteins are highly similar in a region of 19 amino acids near the amino-terminal end (Fig. $4 B$ ). Other regions of the protein sequence show less similarity, although several conserved amino acid residues are interspersed throughout the length of the predicted proteins. Comparisons with the sequences of other vertebrate homeobox genes of the distal-less family (Fig. 5) indicate that $d l \times 2$ is probably the ortholog of the mouse Dlx2 (Tes-1; Porteus et al., 1991; Robinson et al., 1991) and the Xenopus $X$-dll4 and $X$-dlll genes (Dirksen et al., 1993; Papalopulu and Kintner, 1993). The Xenopus $X$-dlll and $X$-dll4 are very similar $(92 \%$ identity), and it is not yet clear whether they are distinct genes or two alleles of the same gene. The zebrafish dll 3 gene is probably the ortholog of the ncwt NvHBoX-4 (Beauchemin and Savard, 1992) and Xenopus X-dll 2 (Papalopulu and Kintner, 1993) genes, and $d l \times 4$ is most likely the ortholog of the Xenopus $X$-dll 3 (Papalopulu and Kintner, 1993) gene. 
The products of the distal-less genes differ from the Antennapedia class of homeodomain proteins that, in vertebrates, are organized into multigene complexes such as the mouse HoxA through $H o x D$ complexes. However, $D l \times 1$ and $D l \times 2$ are linked and located near the HoxD complex on mouse chromosome 2 (McGuinness et al., 1992; Ozcelik et al., 1992). It will now be interesting to determine if two or more of the zebrafish $d l x$ genes are linked, thus suggesting that like the Hox genes, $d l x$ genes evolved as linked multigene complexes. If a fourth zebrafish $d l x$ gene belonging to the $d l x l$ orthologous group exists and if linkage has been conserved, this fourth $d l x$ gene would probably be linked to $d l x 2$. Linkage could provide an explanation for the large number of conserved amino acid residues among the three $d l x$ genes, because linkage would facilitate gene conversion events that rcsult in sequence conservation among genes, provided the conversions affect amino acid residues that do not influence the functional specificity of the protein.

\section{Combinatorial expression of $\mathrm{dlx}$ genes}

The three zebrafish $d l x$ genes resemble each other not only in the sequences of their predicted protein products but also in some but not all aspects of their embryonic patterns of expression. These patterns, summarized in Table 1, suggest that distinct combinations of functionally active $d l x$ genes participate in the development of specific regions of the embryo. The forebrain expresses a combination of $d l \times 2$ and $d l x 4$. The olfactory placodes, the auditory vesicle, and the median fin fold or their precursors express, at some stages of their development, a combination of $d l x 3$ and $d l x 4$. Cells in the primordia of the visceral arches express all three $d l x$ genes, but the developmental time course of expression is unique for each gene.

Comparisons of gene expression patterns among the three zebrafish $d l x$ genes and related genes from other vertebrates suggest a conservation of function among orthologs. The combinatorial expression that we observe for the zebrafish genes may also be found for the distal-less genes of other vertebrates. For example, the regions of the forebrain that express $d l x 2$ and $d l \times 4$ in zebrafish appear to correspond to the forebrain regions that express the orthologs $X$-dll/4 and $X$-dll3, respectively, in Xenopus (Papalopulu and Kintner, 1993), and $d l \times 2$ in the mouse (Bulfone et al., 1993b). In the telencephalon, differences between the zebrafish $d l \times 2$ and $d l \times 4$ expression patterns are reflected in the patterns of their Xenopus orthologs, $X$-dll 4 and $X$-dll3, respectively. No differences between the expression patterns of the $D l x 1$ and $D l \times 2$ genes in the forebrain of the mouse have yet been reported. In contrast, and consistent with this conservation of the expression patterns of orthologous genes, cells of the forebrain fail to express two members of the $d l \times 3$ orthologous group, the zebrafish $d l \times 3$, and the Xenopus $X$-dll2 genes (Fig. $9 B$; Papalopulu and Kintner, 1993). The corresponding information is presently unavailable for the third member of this group, the newt $N v H B O X-4$ gene (Beauchemin and Savard, 1992). Combinatorial expression among spccics scems to apply also to the auditory vesicle. Cells of the auditory vesicle express two members of the $d l \times 4$ group (Fig. $9 F$; Papalopulu and Kintner, 1993), but not members of the $d l x 2$ group. The auditory vesicle also expresses the zebrafish $d l x 3$ gene (Ekker et al., 1992a). Unfortunately, because $d l x 3$ is the only member of this group for which embryonic patterns of expression have been described, it is not yet possible to determine whether this aspect of dl $x 3$ expression is conserved among species. Finally, expression of members of the $d l \times 3$ and $d l \times 4$ orthologous groups in the olfactory placodes is well conserved between zebrafish and Xenopus (there is no information on the expression of $X$-dll 2 in the olfactory placodes). Similarly, the zebrafish and Xenopus olfactory placodes fail to express members of the $d l x 2$ group. We suggest that many aspects of the combinatorial expression of $d l x$ genes have been well conserved during evolution. Characterization of additional $d l x$ genes in the mouse and in other species is required to learn how general this finding may be.

The three regions that express both $d l \times 3$ and $d l \times 4$ after $16 \mathrm{~h}$, the olfactory placode and epithelium, the auditory vesicle, and the median fin fold, each appear to derive from cells that, at the end of gastrulation, express $d l x 3$ (Table 1). It is thus possible that $d l x 3$ expression in a subset of ectodermal cells persists in descendants of these cells and is related to the later expression of the $d l x 4$ gene (but not $d l \times 2$ ) and that the combined expression of the $d l x 3$ and $d l \times 4$ proteins in a given cell participates in the regulatory mechanisms that influence the fate or the state of differentiation of this cell.

Similarly, expression of $d l x 2$ in the precursors of the branchial arches may be related to the later expression of $d l \times 3$ and $d l \times 4$. Development of the branchial arches requires interactions between the neural crest cells that have migrated to this region and mesodermally derived cells (Noden, 1980, 1988). The expression of $d l x 2$ by neural crest cells in the hindbrain region that contributes crest to the branchial arches suggests that $d l \times 2$ expressing neural crest cells may migrate and contribute to the branchial arch region. Expression of $d l \times 3$ and $d l \times 4$ would be activated, following migration, in the same crest cells that express $d l x 2$ and/or in mesodermally derived cells as a result of interactions with these crest cells. The labeling of premigratory neural crest cells and the analysis of labeled cells after migration for the presence of $d l x$ transcripts will help clarify this issue.

The segmental patterning of hindbrain neural crest cell migratory pathways, as marked by $d l \times 2$-expressing cells (Fig. $7 B$ ), matches the migratory patterns of hindbrain crest cells in chicks (Lumsden et al., 1991). In zebrafish, this patterning probably arises from the directed migration of crest cells as they leave the hindbrain, rather than from the absence of crest contributions from rhombomeres 3 and 5, as suggested for chick (Lumsden et al., 1991), because we see $d l \times 2$-positive cells in rhombomeres 3 and 5 prior to migration (Fig. $7 \mathrm{~A}$ ) and because previous fate mapping (Schilling, 1993) suggests that these rhombomeres, in addition to the others, can contribute crest to the branchial arches. Recent fate mapping in the chick agrees with this view that all rhombomeres can contribute neural crest cells to the branchial arches (Sechrist et al., 1993).

Migrating neural crest cells express $d l x 2$ in the mouse (Bulfone et al., 1993a) and $d l \times 2$ in zebrafish (Fig. $7 B$ ). The most closely related Xenopus gene, $X$-dll 4 , does not seem to be expressed in premigratory neural crest cells (Papalopulu and Kintner, 1993), and its expression in migrating neural crest cells has not been reported.

Our results suggest that homeobox genes, in addition to those of the Antennapedia class, may provide combinatorial homeobox gene codes. We have previously observed the coordinate expression of zebrafish engrailed genes at the midbrain-hindbrain junction, in the jaw, and in myotomal muscle pioneers (Ekker et al., 1992b) and the coordinate expression of zebrafish members of the $m s x$ homeobox gene family in macular cells of the inner ear (Ekker et al., 1992a). The results of the present study add the $d l x$ genes to this growing list of potential tran- 

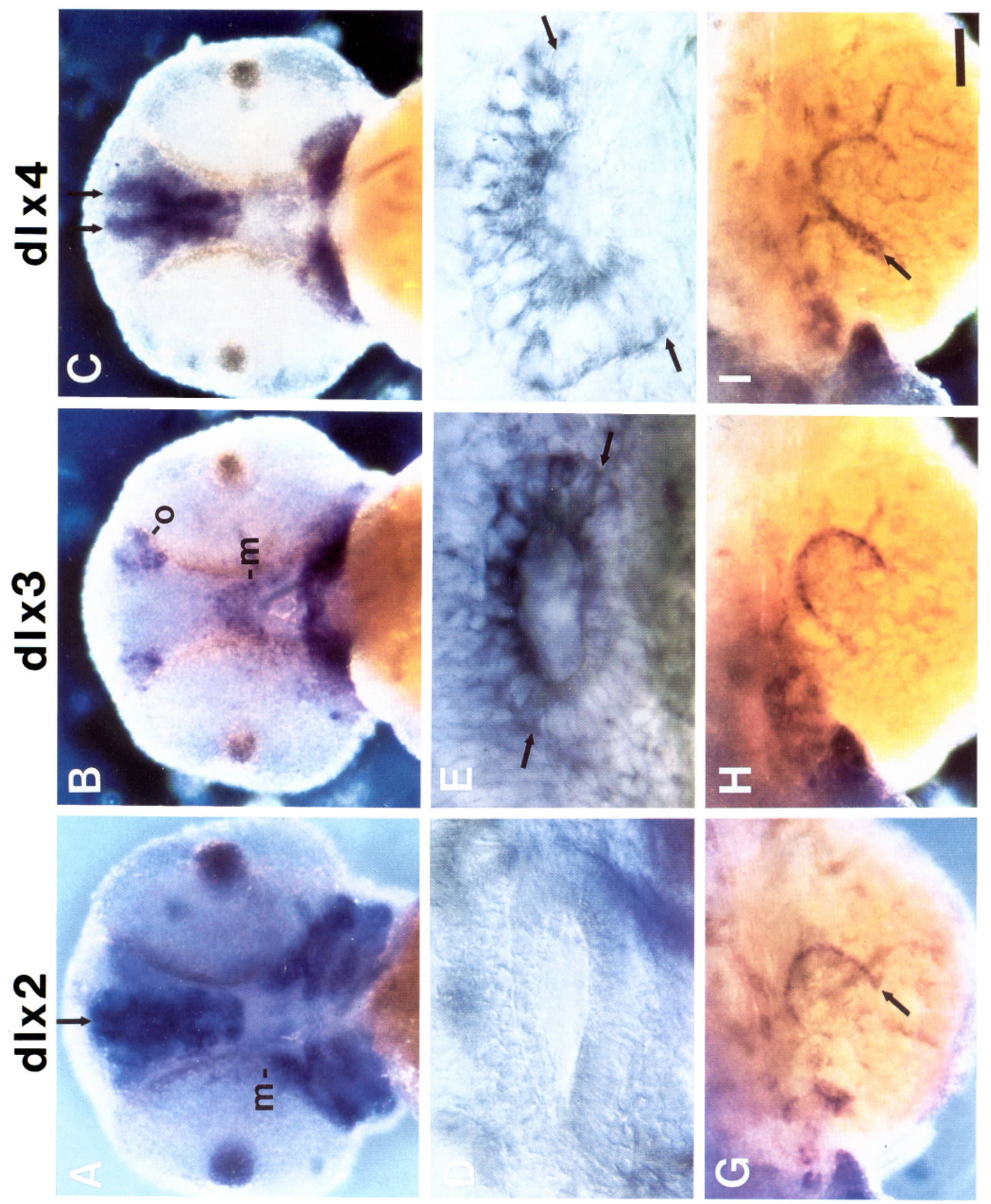

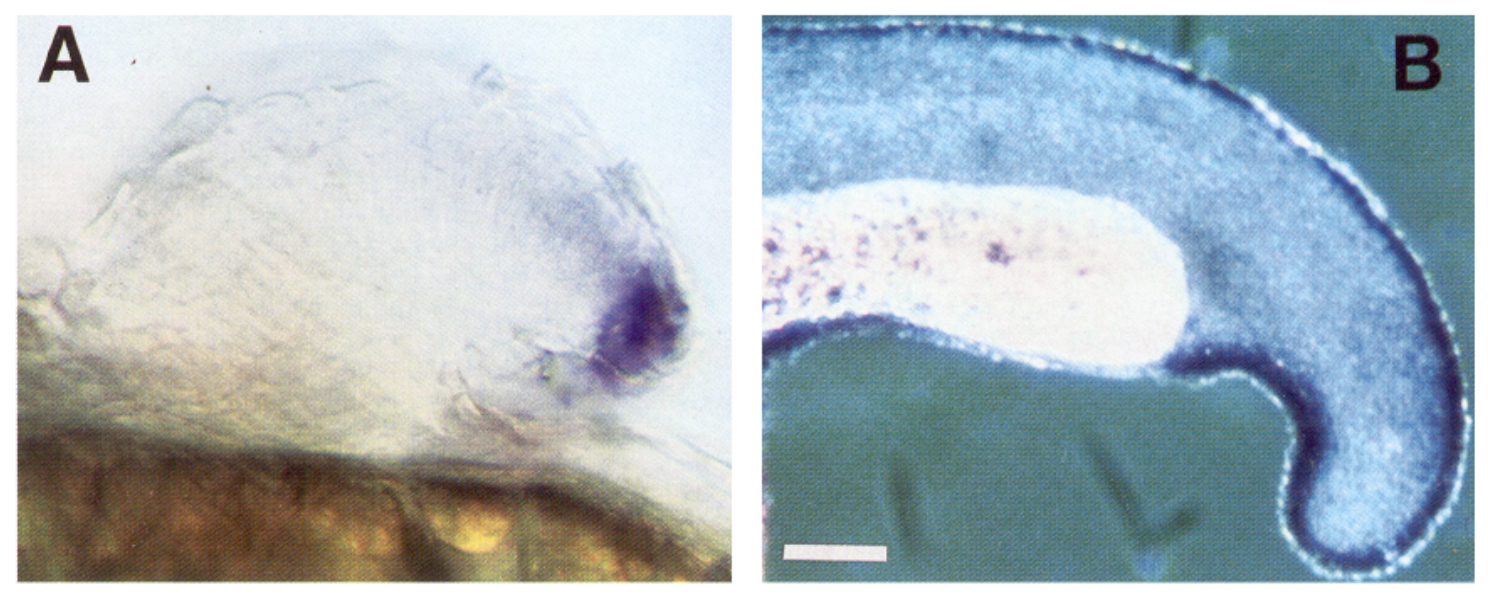

Figure 10. Cells of the fins express the $d l x$ genes. $A$, Cells in the tip of the extending pectoral fin express the $d l x 2$ gene, shown here at $55 \mathrm{~h} . B$, Cells of the caudal fin fold express $d l x 3$, shown here at $24 \mathrm{~h}$. Scale bar: $25 \mu \mathrm{m}$ for $A, 100 \mu \mathrm{m}$ for $B$.

scriptional regulators that appear in discrete regions of the head when cells are differentiating into various types.

Regulatory mechanisms involving combinatorial expression of structurally related proteins could be based upon the formation of multiprotein complexes, competition at similar DNA binding sites for accessory transcription factors, or both, resulting in the activation or repression of specific target genes. Synergistic activation of transcription, mediated by related homeodomain proteins, has been described in vitro (Han et al., 1989) and may require the DNA binding activity of only one of the homeodomain protein partners (Ananthan et al., 1993). The elucidation of such mechanisms in vivo will enhance our understanding of the genetic control of development and will provide valuable information about how developmental strategies involving multigene families evolved.

\section{References}

Akimenko M-A, Ekker M, Westerfield M (1991) Characterization of three zebrafish genes related to Hox-7. In: Developmental patterning of the vertebrate limb (Hinchliffe JR, Hurle, JM, Summerbell D, eds), pp 61-63. New York: Plenum.

Ananthan J, Baler R, Morrissey D, Zuo, J, Lan Y, Weir M, Voellmy R (1993) Synergistic activation of transcription is mediated by the N-teminal domain of Drosophila fushi tarazu homeoprotein and can occur without DNA binding by the protein. Mol Cell Biol 13:15991609.

Asano M, Emori Y, Saigo K, Shiokawa K (1992) Isolation and characterization of a Xenopus cDNA which encodes a homeodomain highly homologous to Drosophila distal-less. J Biol Chem 267:50445047.

Beauchemin M, Savard P (1992) Two distal-less related homeoboxcontaining genes expressed in regeneration blastemas of the newt. Dev Biol 154:55-65.

Boncinelli E, Somma R, Acampora D, Pannese M, D’Esposito M, Faiella A, Simeone A (1988) Organization of human homeobox genes. Hum Reprod 3:880-886.

Bulfone A, Kim H-J, Puelles L, Porteus MH, Grippo JF, Rubenstein
JLR (1993a) The mouse $D l x-2$ (Tes- 1 ) gene is expressed in spatially restricted domains of the forebrain, face and limbs in midgestation mouse embryos. Mech Dev 40:129-140.

Bulfone A, Puelles L, Porteus MH, Frohman MA, Martin GR, Rubenstein JLR (1993b) Spatially restricted expression of $D l x-1, D l x-$ $2(T e s-1), G b x-2$ and $W n t-3$ in the embryonic day 12.5 mouse forebrain defines potential transverse and longitudinal segmental boundaries. J Neurosci 13:3155-3172.

Cohen SM, Bronner G, Kuttner F, Jurgens G, Jäckle H (1989) Distalless encodes a homeodomain protein required for limb development in Drosophila. Nature 338:432-434.

Dirksen M-L, Mathers P, Jamrich M (1993) Expression of a Xenopus distal-less homeobox gene involved in forebrain and cranio-facial development. Mech Dev 41:121-128.

Dolle P, Price M, Duboule D (1992) Expression of the murine Dlx- 1 homeobox gene during facial, ocular and limb development. Differentiation 49:93-99.

Duboule D, Dollé P (1989) The structural and functional organization of the murine Hox gene family resembles that of Drosophila homeotic genes. EMBO J 8:1497-1505.

Ekker M, Akimenko M-A, Bremiller R, Westerfield M (1992a) Regional expression of three homeobox transcripts in the inner ear of zebrafish embryos. Neuron 9:27-35.

Ekker M, Wegner J, Akimenko, M-A, Westerfield M (1992b) Coordinate expression of three zebrafish engrailed genes. Development 116:1001-1012.

Gaunt SJ, Sharpe PT, Duboule D (1988) Spatially restricted domains of homeo-gene transcripts in mouse embryos: relation to segmented body plan. Development [Suppl] 104:169-179.

Graham A, Papalopulu N, Krumlauf R (1989) The murine and Drosophila homeobox clusters have common features of organization and expression. Cell 57:367-378.

Han K, Levine MS, Manley JL (1989) Synergistic activation and repression of transcription by Drosophila homeobox proteins. Cell 56: 573-583.

Hunt P, Gulisano M, Cook M, Sham M, Faiella A, Wilkinson D, Boncinelli E, Krumlauf R (1991a) A distinct Hox code for the branchial region of the head. Nature 353:861-864.

Hunt P, Wilkinson D, Krumlauf R (1991b) Patterning of the vertebrate head: murine Hox2 genes mark distinct subpopulations of premigratory and migrating neural crest. Development 112:43-50.

Figure 9. Combinatorial expression of the three $d l x$ genes in the head. $A-C$, Ventral views (with anterior to the top) of $55 \mathrm{~h}$ embryos hybridized with $d l x 2(A), d l x 3(B)$, or $d l x 4(C)$ probes. The arrows indicate the medially $(A)$ and bilaterally $(C)$ located cells in the telencephalon expressing $d l \times 2(A)$ and $d l \times 4(C)$, respectively. $D-F$, Cells of the auditory vesicle express $d l x 3(E)$ and $d l x 4(F)$, but not $d l x 2(D)$ at 24 h. Side view; arrows indicate the ventral limits of expression within the vesicle. $G-I$, Cells in the AER of the pectoral fin bud express $d l \times 2(G), d l x 3(H)$, and $d l x 4(I)$ in overlapping but distinct patterns at $28 \mathrm{~h}$. Arrows indicate the posterior $(G)$ or anterior $(I)$ extent of expressing cells. The blue signal in the lens $(A-C)$ is probably due to background labeling because it appears variably with all probes. $m$, mandibular arch; $o$, olfactory pit; dorsal is to the top and anterior to the left in $D-I$. Scale bar: $85 \mu \mathrm{m}$ for $A-C$ and $G-I, 16 \mu \mathrm{m}$ for $E$ and $F, 25 \mu \mathrm{m}$ for $D$. 
Jegalian BG, DeRobertis EM (1992) Homeotic transformations in the mouse induced by overexpression of a human Hox 3.3 transgene. Cell 71:901-910.

Kessel M, Gruss P (1991) Homeotic transformations of murine vertebrae and concomitant alterations of Hox codes induced by retinoic acid. Cell 67:89-104

Kessel M, Balling R, Gruss P (1990) Variations of cervical vertebrae after expression of a $H o x 1.1$ in transgene in mice. Cell 61:301-308.

Le Mouellic H, Lallemand Y, Brûlet P (1992) Homeosis in the mouse induced by a null mutation in the Hox-3.1 gene. Cell 69:251-264.

Lewis EB (1978) A gene complex controlling segmentation in Drosophila. Nature 276:565-570.

Lumsden A, Sprawson N, Graham A (1991) Segmental origin and migration of neural crest cells in the hindbrain region of the chick embryo. Development 113:1281-1291.

McGinnis W, Krumlauf R (1992) Homeobox genes and axial patterning. Cell 68:283-302.

McGuinness TL, MacDonald GP, Koch TK, Rubenstein JLR (1992) Evidence for linkage of Tes- 1 and $d l x-1$, two homeobox genes expressed in the developing mammalian forebrain. Soc Neurosci Abstr $18: 956$

Morgan BA, Izpisúa-Belmonte J-C, Duboule D, Tabin CJ (1992) Targetted misexpression of Hox-4.6 in the avian limb bud causes apparent homeotic transformations. Nature 358:236-239.

Noden DM (1980) The migration and cytodifferentiation of cranial neural crest cells, pp 3-25. Amsterdam: Elsevier.

Noden DM (1988) Interactions and fate of avian craniofacial mesenchyme. Development [Suppl] A103:121-140.

Uxtoby E, Jowett ' I' (1993) Cloning of the zebrafish krox-20 gene ( $k r x$ 20 ) and its expression during hindbrain development. Nucleic Acids Res 21:1087-1095.

Ozcelik T, Porteus MH, Rubenstein JLR, Francke U (1992) $D L X 2$ (TES1), a homeobox gene of the distal-less family assigned to conserved regions on human and mouse chromosome 2 . Genomics 13: 1157-1161.

Papalopulu N, Kintner C (1993) Xenopus distal-less related homeobox gencs are cxpressed in the developing forebrain and are induced by planar signals. Development 117:961-975.

Pollock RA, Jay G, Bieberich CJ (1992) Altering the boundaries of Hox3.1 expression: evidence for antipodal gene regulation. Cell 71 : 911-923.

Porteus MH, Bulfone A, Ciaranello RD, Rubenstein JLR (1991) Iso- lation and characterization of a novel cDNA clone encoding a homeodomain that is developmentally regulated in the ventral forebrain. Neuron 7:221-229.

Price M, Lemaistre M, Pischetola M, Di Lauro R, Duboule D (1991) A mouse gene related to distal-less shows a restricted expression in the developing forebrain. Nature 351:748-751.

Püschel AW, Gruss P, Westerfield M (1992) Sequence and expression pattern of pax- 6 are highly conserved between zebrafish and mice. Development 114:643-651.

Robert B, Sassoon D, Jacq B, Gehring W, Buckingham M (1989) Hox7 , a mouse homeobox gene with a novel pattern of expression during embryogenesis. EMBO J 8:91-100.

Robinson GW, Wray S, Mahon KA (1991) Spatially restricted expression of a member of a new family of murine distal-less homeobox genes in the developing forebrain. New Biol 3:1183-1194.

Saitou N, Nei M (1987) The neighbor-joining method: a new method for reconstructing phylogenetic trees. Mol Biol Evol 4:406-425.

Schilling TG (1993) Cell lineage and mutational studies of cranial neural crest development in the zebrafish embryo. PhD thesis, University of Oregon.

Sechrist J, Serbedzija GN, Scherson T, Fraser SE, Bronner-Fraser M (1993) Segmental migration of the hindbrain neural crest does not arise from its segmental generation. Development 118:691-703.

Vachon G, Cohen B, Pfeifle C, McGuffin ME, Botas J, Cohen SM (1992) Homeotic genes of the Bithorax complex repress limb development in the abdomen of the Drosophila embryo through the target gene distal-less. Cell 71:437-450.

Warga RM, Kimmel CB (1990) Cell movements during epiboly and gastrulation in zebrafish. Development 108:569-580.

Westerfield M (1993) The zebrafish book. Eugene, OR: University of Oregon Press.

Wilson SW, Ross LS, Parrett T, Easter SS Jr (1990) The development of a simple scaffold of axon tracts in the brain of the embryonic zebrafish, Brachydanio rerio. Development 108:121-144.

Wood A (1982) Early pectoral fin development and morphogenesis of the apical ectodermal ridge in the killifish, Aphyosemion scheeli. Anat Rec 204:349-356.

Wright CVE, Cho KWY, Hardwicke J, Collins RH, DeRobertis EM (1989) Interference with the function of a homeobox gene in Xenopus embryos produces malformations of the anterior spinal cord. Cell 59: 81-93. 